\title{
Espiritualidade queer
}

(Queer Spirituality)

(Espiritualidad queer)

ISSN: $2358-0844$

n. 14, v. 2

André S. Musskopf ${ }^{1}$

nov.2020-abr.2021

p.1-14

RESUMO: O artigo reflete sobre o que poderia ser uma "espiritualidade queer" para além das abordagens mais comuns sobre as experiências de pessoas LGBTI+ no campo religioso, tanto em termos de vivência de uma religiosidade particular, quanto de como são tratadas pelas religiões. Parte de uma reflexão bíblica teológica sobre "espírito", apontando para a sua instabilidade, fugacidade e multiplicidade, e articula essa compreensão com os significados e implicações de utilização do "queer" no campo religioso. Utiliza-se de reflexões acadêmicas, de pesquisas e de elementos menos ortodoxos (como narrativas diversas) para estabelecer uma relação entre a espiritualidade e o erótico e refletir sobre a experiência do sagrado no cotidiano. Por fim, ensaia uma linguagem religiosa relacionada com narrativas sexuais a partir de uma prática de pesquisa participante.

PALAVRAS-CHAVE: Espiritualidade queer. Erótico. Marcella Althaus-Reid. Indecência. Teologia queer.

Abstract: This article reflects on what could be a "queer spirituality" beyond the more common approaches about the experiences of LGBTI+ people in the religious field, concerning both lived experiences of a particular religiosity, and how they are treated by religions. It starts from a biblical theological reflection about "spirit", pointing to its instability, fugacity and multiplicity, and articulates this understanding with the meanings and implications of the use of "queer" in the religious field. Academic reflections, researches and less orthodox elements (such as diverse narratives) are used to establish a relation between spirituality and the erotic, and reflect about the experience of the sacred in daily life. Finally, it proposes a religious language related to the sexual narratives from the practice of participatory research.

Keywords: Queer spirituality. Erotic. Marcella Althaus-Reid. Indecency. Queer theology.

Resumen: Este artículo reflexiona sobre lo que podría ser una “espiritualidad queer” más allá de los enfoques más comunes sobre la experiencia de personas LGBTI+ en el campo religioso, tanto por las experiencias vividas en una religiosidad particular como de la forma en que son tratadas por las religiones. Primero, hace una reflexión bíblica teológica sobre "espíritu", señalando su instabilidad, fugacidad y multiplicidad, y la articula con los significados e implicaciones del uso de "queer" en el campo religioso. Con base en reflexiones académicas, investigaciones y elementos menos ortodoxos (como narrativas diversas), el texto establece una relación entre la espiritualidad y el erotismo y reflexiona sobre a experiencia de lo sagrado en el cotidiano. Por fin, ensaya un lenguaje religioso relacionado a las narrativas sexuales de la práctica de investigación participante.

Palabras clave: Espiritualidad queer. Erótico. Marcella Althaus-Reid. Indecencia. Teología queer.

1 Doutor em Teologia. Professor do Departamento de Ciência da Religião da Universidade Federal de Juiz de Fora. asmusskopf@hotmail.com. 


\section{Introdução}

Uma abordagem queer sobre o tema da espiritualidade geralmente assume como ponto de partida a forma como 'pessoas queer' vivem sua espiritualidade. Dessa forma, assume-se, quase sempre, uma pretensa unidade identitária compartilhada por pessoas identificadas como ‘queer’, por mais 'queer' que elas sejam entre si. Na verdade, mantem-se as quase tradicionais categorias lésbicas-gays-bissexuais-travestis-transexuais-transgênero-intersexuais, ou qualquer uma das siglas que se utilize para expressar a multiplicidade de identificações disponíveis para as múltiplas variações e entrecruzamentos entre sexo, gênero e sexualidade (sem contar outros marcadores de identidade), e busca-se refletir sobre como as pessoas efetivamente identificadas ou identificáveis com essas categorias ‘vivem a sua espiritualidade’ - ou poderiam vivê-la.

Essa abordagem, sem dúvida, é válida e importante para muitas pessoas que assim se identificam e, muitas vezes, por causa dessa identificação, encontram dificuldade em re/conciliar suas experiências de sexo, gênero e sexualidade com o que anseiam no âmbito da espiritualidade. Em muitos casos, isso pode significar encontrar elementos em uma dada tradição religiosa que permitam a inclusão de experiências particulares e diferentes das normas prescritas para o sexo, o gênero e a sexualidade, preservando a tradição e acomodando alguns elementos estranhos (queer). Em outros casos, isso pode significar buscar tradições ou práticas religiosas que aceitem e reconheçam essas estranhezas (queerness), tanto a ponto de visibilizá-las quanto mantendo-as invisíveis - como se elas não fizessem diferença alguma. Ainda em outros casos isso pode significar criar ou recriar formas distintas de viver a espiritualidade, tanto adaptando elementos e práticas disponíveis em distintas tradições, quanto inventando novas formas de espiritualidade.

Todas essas abordagens apontam, pelo menos, para o fato de que não se pode falar em “espiritualidade” (no singular), mas que se está lidando com uma multiplicidade de expressões que respondem, justamente, à multiplicidade de experiências no campo do sexo, do gênero e da sexualidade em relação àquilo que se está chamando, provisoriamente, de “espiritualidade”. Em certo sentido, inclusive desde uma perspectiva ecumênica e inter-religiosa, isso já é, por si só, queer, pois pensar em qualquer forma de espiritualidade única que pudesse caber sob esse termo ou conceito seria um contrassenso. Nesse sentido, aponta também para o fato de que a espiritualidade, assim como o sexo, o gênero e a sexualidade (para ficar nesse âmbito de experiências humanas e marcadores identitários), é sempre vivenciada no contexto de experiências históricas e culturais concretas e específicas, estando estreitamente ligada a aspectos 
antropológicos e sociológicos de um determinado lugar e de um determinado tempo. Espiritualidade também é contingência.

Um outro elemento que emerge dessas abordagens, e que é relevante do ponto de vista queer, é justamente o fato de que, no contexto das experiências históricas e culturais, sexo, gênero e sexualidade são elementos que interferem na forma como as pessoas vivenciam sua espiritualidade. Muitas vezes se discute, por exemplo, as situações particulares que pessoas identificadas como queer ou LGBTI+ experimentam em consequência de seu sexo, seu gênero e/ou sua sexualidade e como elas se refletem na vivência de sua espiritualidade. Ao se encontrarem em oposição à heteronorma, essas pessoas enfrentam, por exemplo, situações de sofrimento e de violência, mas também de solidariedade e libertação, que podem ser lidas dentro dos marcos referenciais oferecidos por diversas religiões. Outras vezes, se discute, ainda, como determinadas experiências de pessoas queer lograram existir e resistir, mesmo dentro de tradições heteronormativas, em geral sendo invisibilizadas ou apagadas, e se propõe resgatá-las e ressignificá-las no atual contexto, servindo de inspiração para pessoas queer hoje.

Todas essas abordagens são relevantes e contribuem significativamente para a vida das pessoas. Cada uma, em determinados contextos, tem a possibilidade de ser um fator decisivo entre a vida e a morte, entre uma vida vivida em plenitude e uma vida de sofrimento e culpa. Nessa abordagem, no entanto, propõe-se uma perspectiva diferente dessas e, ao invés de discutir a questão queer em relação à espiritualidade, discute-se a espiritualidade em relação ao queer. Em forma de pergunta, isso poderia ser expresso da seguinte forma: o que o conceito "queer” tem a contribuir para uma compreensão sobre espiritualidade? Existe ou é possível pensar em uma espiritualidade eminentemente queer e como se expressaria essa forma de espiritualidade?

Com isso não se pretende afirmar que essa questão já não tenha sido colocada ou discutida. Também não se quer colocar essa abordagem em contraposição às mencionadas acima ou quaisquer outras. Trata-se de um exercício especulativo que, ainda assim, está baseado na produção teórica no amplo campo dos chamados estudos queer e nas experiências concretas nas quais ele se sustenta, bem como em experiências pessoais do autor. Nesse exercício, se permanecerá dentro de um campo religioso específico - a tradição cristã.

O tema "espiritualidade”, especialmente quando tratado em relação à perspectiva queer, não pode ser encapsulado dentro de uma determinada tradição, o que seria, novamente, um contrassenso. Estudos clássicos do campo da sociologia da religião, como os de Clifford Geertz (2008) e Rudolf Otto (2007), por exemplo, seriam suficientes para esticar o conceito de espiritualidade para além de qualquer fronteira religiosa específica. As próprias práticas e construções de teólogas e grupos feministas consideradas pós-cristãs, entre outras, seriam 
suficientes para explodir qualquer tentativa de tornar queer o cristianismo, considerando suas raízes e heranças heteropatriarcais. Está evidente que o conceito de espiritualidade não pode ser circunscrito ao conceito de religião - nem na teoria e nem na prática.

Ainda que se permaneça dentro desse marco de referência, não se assume uma perspectiva cristã fundamentalista ou conservadora (no sentido opressivo que esses termos e conceitos podem assumir em determinados discursos e práticas), possivelmente podendo ser inscrito por essas perspectivas como uma abordagem "pós-cristã”. Essa reflexão se insere naquilo que pode ser chamado de maneira ampla de “cristianismo da libertação", assim como desenvolvido a partir das religiosidades populares no Brasil e na América Latina, e formulado em muito do que é conhecido como "teologias da libertação". Não se pretende, no entanto, qualquer sentimento ou intenção de fidelidade e familiaridade (entendidas em suas acepções heternormativas) a qualquer linha de pensamento ou grupo específico.

Outro aspecto relevante para essa abordagem é que “queer”, no Brasil, e, de modo geral, na América Latina, não é um termo ou conceito traduzido em termos de identidade - assim como se percebe em outros contextos, particularmente nos de fala inglesa. Embora haja uma certa familiaridade com o termo "queer" e suas conotações em seus contextos de origem, tanto no âmbito dos estudos acadêmicos quanto de grupos ativistas e movimentos sociais, esse não é um termo que se pode encontrar facilmente associado a nenhuma identidade específica (ainda quando essa seja queer) ou a alguma prática socialmente definida e também é “estranha” à grande parte da população. Nesse ponto, para essa reflexão, “queer” assume tanto a dificuldade de ser reconhecido como parte da linguagem corrente (inclusive por se tratar de um idioma estranho), quanto a possibilidade de que, de fato, pode ser tomado como "uma trama aberta de possibilidades, brechas, sobreposições, dissonâncias e ressonâncias, lapsos e excessos de significado” (SEDGWICK, 1993, p. 8), visto que não se assimila a nenhuma identidade específica a esse contexto.

\section{Tradição bíblica - a espiritualidade do queer}

Como já discutido, buscar uma forma única e monossêmica de definir espiritualidade seria trilhar o caminho oposto ao que uma abordagem queer propõe e resultaria, inevitavelmente, em formulações que, por mais inclusivas e acolhedoras que parecessem, acabariam sendo excludentes e opressoras. O próprio conceito de queer implica que, qualquer que seja a realidade em discussão, uma tentativa de encontrar uma formulação definitiva e universalmente aplicável, não passará o teste da realidade que sempre escapa a qualquer conceito ou definição fechada. 
Nessa perspectiva, poder-se-ia dizer, desde já, que há algo de “espiritual” ou “sagrado” no próprio conceito queer, que não se permite conhecer ou definir em sua plenitude, mas apenas em parte(s) ${ }^{2}$.

Para iniciar essa reflexão sobre "espiritualidade queer” propõe-se utilizar elementos da tradição bíblica para pensar a espiritualidade. O próprio texto bíblico não pode ser resumido a apenas “uma tradição”, mas é, ele mesmo, uma bricolagem de tradições diversas, tanto dentro de uma perspectiva temporal, quanto geográfica e cultural, mas também teológica. Essas mesmas tradições presentes nos textos bíblicos foram retrabalhadas em séculos de tradição interpretativa, gerando, também, tradições diversas em termos temporais, geográficos, culturais e teológicos, cuja maior prova são as diversas correntes e denominações cristãs existentes. A ideia de unicidade e harmonia propalada especialmente por grupos fundamentalistas (que optam por uma determinada corrente e perspectiva interpretativa) não resistiria à mais simples leitura intertextual da própria Bíblia - o que não significa que lideranças e grupos que utilizam essas perspectivas não tenham grande sucesso em seu apelo e capacidade política de intervir nas mais diversas questões.

Assim, não se pretende aqui esboçar uma teoria sobre como se deve compreender corretamente - o tema da espiritualidade a partir da Bíblia. Parte-se do pressuposto de que há diversas formas possíveis de compreender e elas estão associadas às perspectivas e experiências de quem se aproxima do texto. Reivindica-se apenas a autoridade de aproximar-se do texto e, a partir da experiência, buscar sentido para o que se está chamando de espiritualidade.

Talvez não haja nada mais “queer” na tradição bíblica do que a forma como entende e expressa "espírito" e as formas de experimentar essa realidade na vida cotidiana “espiritualidade”. A própria representação “do” espírito na figura de uma "pomba” na tradição pictórica cristã, diria Marcella Althaus-Reid (BRUM, 2009), é suficiente para imaginar que se está lidando com algo necessariamente “estranho/queer”, particularmente quando pensado numa perspectiva trinitária tradicional na qual “a pomba” se coloca ao lado do Pai e do Filho.

No livro bíblico de Gênesis, capítulo 2, versículo 7 lê-se: "Então formou Deus o ser humano do pó da terra, e lhe soprou nas narinas o fôlego da vida, e o ser humano passou a ser alma vivente”. As imagens do pó, da terra, do barro, do sopro, do fôlego, por si só ou mesmo na tradição bíblica de modo geral, são capazes de evocar uma série de questões relacionadas à espiritualidade. Nishmat - o fôlego da vida; nefesh - alma vivente; estão no mesmo universo de

2 Referência ao texto bíblico encontrado na primeira carta à comunidade de Corinto, capítulo 13, versículo 12, que diz: "Porque agora vemos como espelho, obscuramente, então veremos face a face; agora conheço em parte, então conhecerei como também sou conhecido”. Todas as citações bíblicas são retiradas da Tradução de João Ferreira de Almeida. 
sentido expresso por outro termo Hebraico - ruah, e por termos gregos como pneuma e psiche, ou, ainda, por termos latinos como spiritus e anima. Em certo sentido, os termos gregos e latinos são usados para "traduzir" os termos hebraicos e, nesse processo de tradução e adaptação teológica, seu sentido vai também sendo alterado. Afinal, seria complicado buscar uma associação entre a psique do Novo Testamento (geralmente traduzida como "alma”) e a psique de Freud em sua teoria sobre o inconsciente. A própria comparação é esdrúxula. Serve apenas para explicitar que termos distintos, em idiomas distintos, não são facilmente “traduzíveis”, uma vez que a tradução já compreende uma adaptação dentro de uma outra perspectiva epistemológica.

Seguindo a tradição hebraica, o que todos esses termos preservam em comum é a sua relação com o ar, o vento, o sopro, a respiração. O “ar” (ruah) que paira sobre as águas em Gênesis 1, o “sopro” (nishmat) que dá fôlego (nefesh) ao ser humano em Gênesis 2, estão relacionados com o vento (pnoes) impetuoso que deixou os discípulos e as discípulas cheios e cheias do Espírito (pneumatos) em Atos 2.2, 4. E muitas outras relações poderiam ser construídas a partir do uso desses termos no texto bíblico. Por hora, é suficiente estabelecer que uma das formas primordiais de pensar “espírito” e “espiritualidade” a partir dessa tradição está em associá-los a esse "fenômeno" experimentado de diversas formas e em diversos contextos.

O vento que seca a roupa no varal ou a louça na pia; o vento que faz mover barcos e outros meios de transporte; a brisa leve numa tarde quente de verão; o vento frio e cortante do inverno; o vento que move moinhos e gera energia e o vento que arranca e destrói tudo o que está em seu caminho. O vento soprado na nuca, atrás da orelha, por entre flertes provocantes e juras de amor; o suspiro de surpresa, relaxamento, assombramento; o gemido de prazer, de entrega, de dor; o arrepio que percorre o corpo todo, ouriçando a pele e os sentidos; ofegante. Respiração, inspiração, conspiração. Respirar... o mesmo ar que te rodeia.

O espírito-vento presente no bater das asas da pomba acabou sendo associado a algo invisível, imperceptível e que, apesar de “animar” as pessoas e as coisas carece de materialidade. Na própria tradição filosófica grega, cujas marcas se pode perceber já no Novo Testamento, o espírito (pneuma ou psique) é contraposto ao corpo (soma ou sarx) e o resultado é uma tradição, dentro do próprio cristianismo, que valoriza uma dimensão - a espiritual - em detrimento da outra - a carnal/material. O corpo é associado ao pecado, e o espírito é associado à virtude; e todos os demais binarismos e dualismos bastante conhecidos, assim como bem conhecidos os seus efeitos na vivência da sexualidade de todas as pessoas e, particularmente, na vida de pessoas LGBTI+, marcadas pela forma como vivem e expressam seu sexo, gênero e sexualidade. 
Por isso, uma abordagem queer da espiritualidade precisa partir justamente do corpo e da sexualidade como forma de reclamar a sua materialidade e a sua expressão em todas as dimensões da vida. Afinal, a própria separação entre espírito/alma (nefesh no hebraico, pneuma e psique no grego) e corpo (basar em hebraico, soma e sarx em grego) - note-se a existência de dois termos diferentes em grego para o mesmo termo em hebraico - é estranha ao Antigo Testamento, em que cada um dos termos indica o ser humano em sua integralidade, e, de modo geral, ao próprio Novo Testamento (onde já se percebe algumas influências do pensamento grego). As consequências disso são que uma espiritualidade queer estará profundamente enraizada na corporeidade e nas experiências mais íntimas no campo da sexualidade. A tradição bíblica seguramente oferece os recursos para tal construção. Como diz Ivone Gebara (2007, p. 39), referindo-se à ideia de transcendência, trata-se de "uma experiência dentro da cotidiana materialidade humana, dentro da contingência de nossa história e de nosso planeta”.

\section{Queer o quê? - O queer da espiritualidade}

Até aqui o termo “queer” foi utilizado de maneira bastante livre, associado a construções identitárias de sexo, gênero e sexualidade, a sua etimologia geral em seu idioma de origem, a um conceito "que conota etimologicamente um cruzamento de fronteiras, mas que se refere a nada em particular, por isso deixando a pergunta por suas denotações aberta a contestação e revisão”. (TURNER, 2000, p. 35)

Já é bastante sabido que o termo “queer”, em seu idioma original, tem o significado de “esquisito, singular, estranho, excêntrico...”. É nesse sentido, também, que ele passou a ser atribuído a pessoas com construções de sexo, gênero e sexualidade de maneira diversa das pressuposições normativas, elas mesmas vistas como "esquisitas, singulares, estranhas, excêntricas".

Assim, o próprio movimento social e político que se caracteriza cada vez mais pela multiplicidade de identidades reivindicando suas especificidades, em alguns casos, passou a utilizar o termo como um "guarda-chuva" para abrigar essas múltiplas identidades e identificações. Independentemente de ser lésbica, gay, bissexual, travesti, transexual, transgênero (sem contar aqui as questões de classe social, raça e etnia, geração, diferentes habilidades etc.) a ideia é que todas essas pessoas são ou podem ser, de alguma forma, queer. Neste sentido, o termo queer busca garantir uma maior mobilidade dentro da construção das identidades e “identidades queer são caracterizadas por sua posição contra o normal”. (BLOODSWORTH, 2000, p. 487) 
Já no final da década de 1980 e no início dos anos de 1990, o termo também passou a ser aplicado no campo teórico das discussões de gênero e sexualidade, surgindo o que ficou conhecido como “teoria queer” ou “estudos queer”. Segundo Spargo (1999, p. 36-37): “Foi no contexto do ativismo relacionado com a questão da Aids e da rejeição de estratégias assimilacionistas que 'queer' foi reconfigurado na sua forma corrente tanto na cultura popular quanto na teoria”.

Assim, os estudos queer "interrogam aspectos da vida social - a família, relacionamentos íntimos - mas também olha para lugares não tipicamente pensados como sexualizados - a economia, por exemplo”. (STEIN; PLUMMER, 1996, p. 135) Seguindo a linha de Foucault, estudos históricos mostram que categorias são construídas e atribuídas de acordo com questões de poder e trazem à tona questões de gênero e sexualidade onde antes não se pensava nestes temas, provando que “a vida pessoal é sexualizada - e heterossexualizada”. (STEIN; PLUMMER, 1996, p. 135) A área da sexualidade, suas categorias e construções são a lente que estudiosas e estudiosos queer usam para desenvolver seus trabalhos. Segundo Sedgwick (1993, p. 490): "Porque a sociedade está organizada num modelo heterossexual, desafiar as reivindicações presumíveis de heteronormatividade força o questionamento da lógica de governo, religião, medicina, lei, e cada disciplina que estrutura a vida das pessoas”.

Mas os estudos queer não podem ser enquadrados somente sob a ótica de gênero e sexualidade, pois tratam também das “formas que raça, etnia, nacionalidade pós-colonial num entrecruzamento com [gênero e identidade] e outros discursos de constituição de identidade e fração de identidades” (SEDGWICK, 1993, p. 9) e da necessária interseccionalidade dessas questões.

Nessa reflexão sobre espiritualidade, propõe-se pensar o “queer” simplesmente dessa forma: "um cruzamento de fronteiras, mas que se refere a nada em particular, por isso deixando a pergunta por suas denotações aberta a contestação e revisão”. (TURNER, 2000, p. 35) E a pergunta, então, é: de que forma essa compreensão de “queer” repercute na reflexão teológica e na forma como se pensa a espiritualidade.

Marcella Althaus-Reid, teóloga latino-americana da libertação, teóloga feminista e teóloga queer, em sua proposta de uma teologia indecente propõe a “indecência” como:

um contradiscurso para o desmascaramento [unmasking] e desnudamento [unclothing] dos pressupostos sexuais construídos [...]. Indecência como um gesto sexual é extremamente político e erótico, e se relaciona com a construção da identidade do sujeito através de subversão das identidades econômicas, religiosas e políticas. (ALTHAUS-REID, 2001, p. 168) 
Decência, nesse sentido, é justamente a forma de ordenar e normatizar as identidades e expressões de gênero e sexualidade.

Para Marcella, toda teologia é um ato sexual. Referindo-se às teologias tradicionais a autora afirma que "a teologia é uma ideologia sexual desempenhada [performed] num padrão sacralizador: é uma ortodoxia (dogma sexual correto) e ortopraxis (comportamento sexual correto) sexual divinizada”. (ALTHAUS-REID, 2001, p. 87) Por outro lado, afirma ela: “Na Teologia queer o fundamento da reflexão teológica está em relacionamentos humanos pois [...] é em cenas de intimidade e a epistemologia oferecida por aquelas excluídas e aqueles excluídos do projeto político heterossexual na teologia que revelações [unveiligns] de Deus podem ocorrer” (ALTHAUS-REID, 2003, p. 14) Por isso, ainda segundo a autora: “A conclusão surpreendente é que no tempo presente a revelação precisa ser queer, porque precisa vir de um Deus queer, manifesto nas pessoas cujo estilo de vida e valores não são facilmente assimilados pela espiritualidade capitalista”. (ALTHAUS-REID, 2003, p. 158)

Na discussão sobre espiritualidade, a reflexão de Marcella sobre santidade, desenvolvida no livro The queer god, pode ajudar a pensar esse tema no contexto de uma teologia indecente. Segundo Marcella:

Santidade queer é um caminho de libertar nossas vidas do controle de autoridades, quando essas autoridades justificam sua posição em falsas reivindicações que não podem ser encontradas em um caminho de justiça. Como tal, santas e santos queer são uma ameaça e uma força subversiva pelo simples ato de viver em integridade e de uma maneira desafiadora. (ALTHAUS-REID, 2003, p. 166)

Nessa perspectiva, “... santidade se torna uma tradição de corpos”. (ALTHAUS-REID, 2003, p. 142) E diz a autora:

E a beleza disso é que o Deus Queer, chamando-nos a uma vida de santidade queer, tem estado saindo do armário por muito tempo, em cidades bissexuais da América Latina, na teologia Soq'a de romances sexuais e também entre as pessoas socialmente excluídas vivendo nas favelas de Buenos Aires. Do amor/conhecimento de travestis reunindo-se em solidariedade econômica em pensões na Argentina às Irmãs da Perpétua Indulgência e seu chamado debochado à santidade através de atos de compaixão, o Deus Queer fluído, fluída e instável como nós mesmas e nós mesmos, mas também rindo e tendo prazer enquanto busca um destino divino do tipo de justiça transgressora que desordena a lei - vem em glória e em ressurreição. [...] Esse/essa é o/a Deus queer, estranho, que em nosso tempo e época está mostrando a face de Deus entre pessoas que são amantes de Deus - e amantes queer nesse caso. (ALTHAUS-REID, 2003, p. 171)

\section{Espiritualidade como erótico}

Seguindo a proposta da teologia indecente de Marcella Althaus-Reid, "usando a memória teológica de experiências amorosas não fixáveis e perturbadoras [unsettling] nós deveríamos ser capazes de pensar sobre uma experiência de Deus em movimento como expressa pela retórica de 
um ‘transbordamento erótico divino’”. (ALTHAUS-REID, 2003, p. 44) Uma espiritualidade queer!

Em seu texto sobre “o erótico como poder”, Audre Lorde afirma:

Quando nós começamos a viver de dentro para fora, em contato com o poder do erótico dentro de nós mesmas e nós mesmos, e permitindo que esse poder informe e ilumine nossas ações no mundo e ao nosso redor, então nós começamos a ser responsáveis por nós mesmas e nós mesmos no mais profundo sentido. (LORDE apud KOCH, 2001, p. 15-16)

A partir das reflexões de Audre Lorde sobre o erótico, o biblista Timothy Koch propôs utilizar as práticas de pegação (cruising) como estratégia hermenêutica. Segundo ele, na interpretação de textos ou na produção do conhecimento teológico, isso implica:

\begin{abstract}
“usar nossas próprias formas de conhecimento, nosso próprio desejo por conectar-se, nossa própria compreensão e instinto, nossa própria resposta ao que nos atrai e nos compele [...] Pois, assim como em nossas vidas sociais, escolher fazer pegação aqui significa assumir nossa própria autoridade e responsabilidade em seguir o que quer que entre no nosso caminho, pois é isto que fala aos nossos próprios desejos”. (KOCH, 2001, p. 16)
\end{abstract}

Erótico. Desejo. Espiritualidade. Um testemunho:

Eu tinha estado lá por três horas. Não estava rolando muita coisa. Através da fumaça do vapor e alguns raios de luz eu vi um rapaz baixinho e magrinho. Ele não parecia muito interessado no que estava acontecendo. Através da fumaça do vapor e de alguns raios de luz, enquanto outras pessoas estavam entrando e saindo, inevitavelmente deixando o ar frio entrar e deixando o espaço um pouco menos cheio de vapor e um pouco mais claro, eu segui os seus movimentos, sem saber se ele estava seguindo os meus. Eu apoiei meus cotovelos nos meus joelhos, segurando minha cabeça com minhas mãos, às vezes olhando diretamente para ele, através da fumaça do vapor, às vezes olhando para o meu próprio corpo reagindo à sensação. Eu esperei que ele se tocasse, fizesse qualquer tipo de movimento. E ele fez. Eu me sentei com a coluna ereta, estiquei minhas costas, meus braços, movimentei minha cabeça para cima e para baixo para aliviar a tensão no meu pescoço. Eu me toquei, duro, quase naturalmente ainda me insinuando. E ele fez o mesmo. As toalhas, quase inadvertidamente, revelando um pouco mais, um pouco menos. A excitação, o desejo, crescendo e se tornado mais intenso. Estava quente, e cheio de fumaça do calor, e havia alguns raios de luz. Ele se levantou. Ele segurou sua toalha enquanto a colocava ao redor de sua cintura, assim revelando, no movimento da toalha, seu lado, sua ereção, seu pêlo. Enquanto ele estava saindo eu também levantei, repetindo o movimento. Lá fora com o ar mais claro e com um pouco mais de luz ele foi para o outro espaço. Entrou em um dos espaços privados, separados por paredes finas de madeira, dois metros quadrados, um fino colchonete preto cobrindo o chão, escuro. Eu fechei a porta. Ele soltou sua toalha e ela caiu. Seu corpo magro, franzino, sua ereção totalmente revelada. Eu deixei a minha toalha cair. Devagar 
nós começamos a nos tocar, descobrir. Nós nos beijamos, intensivamente e gentilmente. Nossos corpos se encontraram. Eles se penetraram. Eles se moveram juntos naquele espaço pequeno e escuro de maneiras não imagináveis. Finalmente, nós descansamos. Estávamos molhados. Nossos corpos lentamente esfriaram e nós estávamos um nos braços do outro. Isaque, ironicamente, ele disse que era seu nome. Eu disse o meu. Ele estudava psicologia. Eu era um teólogo. Ele tinha passado seis anos num seminário católico. Eu estava fazendo doutorado. Seu mestrado era sobre Sartre. Eu estava lendo Simone de Beuavoir. Nós falamos sobre relacionamentos, príncipes encantados, vida real. Nos levantamos, tomamos banho e fomos embora. Foi um prazer conhecer você!

O romance A cor púrpura, de Alice Walker (1982), tem muito a dizer sobre teologia e espiritualidade e a sua relação com o erótico. Não há tema ou questão teológica que não possa ser discutido a partir das experiências narradas. Em sua trama, na construção das personagens e nas formas de resistência (particularmente das mulheres), o poder do erótico é a força que liberta, movimenta, empodera e alimenta a superação das formas de opressão e violência e a possibilidade de reconciliação.

Trata-se de uma espiritualidade encarnada, expressa de maneira primorosa na figura de Sofia, uma mulher preta, gorda, que engravida antes do casamento, enfrenta o sogro para casarse com o pai de seu filho, sofre violência doméstica, amparada por suas irmãs consegue sair desse ciclo, mas é novamente atrapada pelo racismo, que faz com que seja presa, torturada e “libertada” sob a condição de servir a uma mulher branca vendo sua vida murchar e apagar.

Seria o ponto final de uma vida de luta e de resistência se não fosse, mais uma vez, pela sororidade vivenciada entre mulheres. Na mesa de jantar, depois de um enfrentamento das mulheres aos homens tiranos, Sofia, que até então mostrava-se sorumbática e confusa começa a rir sem parar. Ela relembra as experiências de violência, dor e sofrimento e como as mulheres a sustentaram nesse caminho. E termina dizendo: "Sofia está de volta; e as coisas vão mudar por aqui" - e começa a comer tudo o que vê pela frente. O riso, o retorno, a fome. "Sofia está de volta; e as coisas vão mudar por aqui”’3!

Celie, a personagem principal da trama, é outra personagem que vai encontrando a si mesma e libertando-se pelo poder do erótico. Deus, para ela, passa de uma figura opressora e que justifica a sua situação de opressão a uma força erótica presente em sua vida através de suas companheiras, através do mundo que a cerca, através das novas formas (subversivas) de vida que ela vai construindo. Em certa passagem, questionada sobre o fato de que estava fumando, ela afirma: "Eu fumo quando eu quero falar com Deus. Eu fumo quando eu quero fazer amor.

3 Essa descrição refere-se a cena do filme The color purple, dirigido por Steven Spielberg. 
Ultimamente eu sinto como se eu e Deus fizéssemos amor numa boa de qualquer forma. Se eu fumo maconha ou não”. (WALKER, 1982, p. 227)

Uma espiritualidade queer é uma espiritualidade centrada no erótico como poder. Que subverte a lógica, que cria comunidade, que sustenta formas justas e amorosas de viver e se relacionar. Na verdade, a própria ideia de espiritualidade, a partir da perspectiva trabalhada neste texto, ou é queer ou não é espiritualidade, mas uma forma disfarçada de controle de corpos e desejos. A espiritualidade é erótica, sopra onde e quando quer, é livre, e acontece ali as pessoas entram em contato com seus desejos, na fricção dos corpos.

\section{Encontrando uma linguagem}

Durante o ano de 2016 foi desenvolvido um trabalho com um grupo de mulheres para discutir saúde e direitos sexuais e reprodutivos ${ }^{4}$. Tratava-se de um grupo ligado a uma comunidade religiosa bastante tradicional, composto por mulheres entre 40 e 80 anos. Seu interesse era discutir o tema da homossexualidade, visto que algumas delas tinham filhas ou filhos homossexuais e não sabiam como lidar com essa questão no contexto da vivência na igreja e da sua experiência de fé.

Propor-se para o grupo que, para falar sobre "homossexualidade” era necessário, também, pensar nas experiências e narrativas sexuais de cada participante. Isso era importante para poder entender de que forma determinadas normas e padrões que excluem as experiências homossexuais engendram também formas de opressão e cerceamento da sexualidade daquelas pessoas que não se entendem dessa forma, mas que, de modo geral, se compreendem estando dentro da norma.

Durante os encontros, a partir da construção de laços de confiança, utilização de metodologias de educação popular e leitura popular da Bíblia, as mulheres foram contando histórias e experiências no campo da sexualidade que revelaram, pouco a pouco, que uma discussão “queer” ou “indecente” sobre sexualidade não pode estar centrada apenas na experiência de pessoas LGBTI+, mas precisa dar conta dos sistemas e padrões que controlam os corpos de todas as pessoas - independentemente de suas identidades e identificações no universo das categorias de sexo, gênero e sexualidade. A miséria social também se expressa na miséria sexual constituinte do sistema capitalista que garante privilégios para alguns e exclui as grandes maiorias do acesso aos bens de produção e reprodução da vida, da garantia de direitos básicos.

4 O relatório completo da pesquisa está publicado em MUSSKOPF et al., 2018. 
Uma das histórias compartilhadas por uma senhora com mais de 80 anos foi sobre algo que ocorreu com sua irmã. Contou a senhora que sua irmã, na noite de núpcias, foi devolvida pelo seu marido à família sob a acusação de que não era mais virgem. A mãe, preocupada com o destino da filha caso a versão do marido se confirmasse, perguntou à filha o que tinha ocorrido. A filha, em meio ao desespero de passar a ser vista como indigna em sua família e em sua comunidade, e todas as possíveis consequências que isso poderia trazer para o seu futuro, contou que o “desvirginamento” fora um acidente. Certo dia, ao caminhar pela roça recém lavrada para levar o almoço para o pai e os irmãos que estavam na lida, tropeçara e o bico da chaleira penetrara sua vagina, rompendo a membrana que supostamente garantia a sua castidade. Contounos a senhora que, de fato, nem a mãe e nem as outras irmãs acreditaram na história, mas essa passou a ser a versão contada e que convencia - e comovia - as demais pessoas da família e da comunidade. Em certo sentido, a chaleira desvirginadora e a cumplicidade das mulheres salvou a irmã do ostracismo social.

Uma das perguntas centrais no trabalho com esse grupo de mulheres era a busca por uma linguagem capaz de falar das experiências no campo da sexualidade no contexto religioso. Como seres de linguagem que se revestem de anseios e sistemas de organização social cotidiana, não é possível pensar uma espiritualidade fora dela. Nesse sentido, a pergunta a ser feita, também, ao refletir sobre uma espiritualidade subversiva, é qual a linguagem, ou quais as linguagens que são capazes de expressar essa perspectiva a partir do cotidiano e da convivência comunitária. Através de uma oração construída com essas mulheres oferece-se uma possibilidade para construir essa linguagem a partir da vivência desse grupo.

"Nossa senhora da chaleira desvirginadora

Rogai por nós mulheres desejantes e desejosas

agora e na hora do hímen rompido. Amém!

Livrai-nos do coito patriarcal que nos invade sem lubrificação

E da calúnia de sermos consideradas impuras e pecadoras

Enchei-nos da graça de orgasmos de todos os tipos

Quando, como e com quem quisermos”

\section{Referências}

ALTHAUS-REID, M. Indecent theology. London: Routledge, 2001.

ALTHAUS-REID, M. The queer god. London: Routledge, 2003. 
BLOODSWORTH, M. K. Queer identity. In: MURPHY, T. F. (ed.). Reader's guide to lesbian and gay studies. Chicago: Fitzroy Deadborn Publishers, 2000. p. 487-488.

BRUM, E. Marcella Althaus-Reid: teologia indecente. Revista Época, Brasil, 2004. Disponível em: https://bityli.com/tJdxM. Acesso em: 5 maio 2020.

GEBARA, I. O que é teologia feminista. São Paulo: Brasiliense, 2007.

GEERTZ, C. A interpretação das culturas. Rio de Janeiro: Livros Técnicos e Científicos, 2008.

KOCH, T. A homoerotic approach to Scripture. Theology \& Sexuality, Abingdon, v. 14, p. 10-22, 2001.

MUSSKOPF, A. S. et al. A produção de conhecimento teológico sobre saúde e direitos no âmbito da sexualidade e da reprodução humana a partir do trabalho com grupos religiosos e organizações sociais. In: MUSSKOPF, A. S.; GONZÁLEZ-BERNAL, E. (org.). Teologia e sexualidade, saúde reprodutiva e direitos: experiências em pesquisa participante. São Leopoldo: Cebi, 2018. p. 25-80.

OTTO, R. O sagrado. Tradução de Walter Schlupp. São Leopoldo: Sinodal/EST, 2007.

SEDGWICK, E. K. Tendencies. Durham: Duke University Press, 1993.

SPARGO, Y. Foucault and queer theory. Cambridge: Icon, 1999.

STEIN, A.; PLUMMER, K. I can't even think straight. In: SEIDMAN, S. (ed.). Queer theory/sociology. Oxford: Blackwell Publishers, 1996. p. 129-144.

TURNER, W. B. A genealogy of queer theory. Philadelphia: Temple University Press, 2000.

WALKER, A. The color purple. New York: Pocket Books, 1982. 